\title{
CORRELATION OF INCREASED TOTAL SERUM IMMUNOGLOBULIN E LEVELS AND HIDRADENITIS SUPPURATIVA
}

\author{
Ballova A, Vorcakova K, Pec J \\ Clinic of Dermatovenerology, Jessenius Faculty of Medicine in Martin, Comenius University in \\ Bratislava, and Martin University Hospital, Martin, Slovak Republic
}

\begin{abstract}
A b s tract
Introduction: Hidradenitis suppurativa is a chronic inflammatory skin disease with a typical formation of inflamed nodules, abscesses, and sinus tracts usually in the axillary, inguinal, and anogenital region. We decided to investigate the possible association of hidradenitis suppurativa and total IgE elevation and to explore the patients' characteristics which can be related to high IgE levels.

Methods: We performed a retrospective observational study which included 67 patients with moderate-to-severe stage of hidradenitis suppurativa followed up in our outpatient dermatology department. Total IgE, IgA, IgG, IgM, and CRP serum levels were measured. A personal and family history was taken. We asked them about allergic diseases and cigarette smoking and determined the basic parameters such as the weight and height of the patients.

Results: Elevated total IgE levels were noticed in 21 patients (31.3\%), of which 6 had a history of allergic disorder. Three of them had allergic rhinoconjunctivitis and the other three were suffering from atopic dermatitis. The mean total IgE level was $203.0 \mathrm{IU} / \mathrm{ml}$ with a maximum value of $1,954 \mathrm{IU} / \mathrm{ml}$. Analysis of the factors, such as cigarette smoking, sex, elevated CRP, body mass index, and the number of affected areas, did not show an association with increased IgE levels.

Conclusion: Our study showed a higher mean value of total IgE in patients with moderate to severe hidradenitis suppurativa than in the general population. However, we did not confirm an association with any characteristics of the patients. Limitations of this work include a small number of patients and a lack of the control group, therefore further and more extensive studies are needed to support these results.
\end{abstract}

Key words: Hidradenitis suppurativa, acne inversa, immunoglobulin $\mathrm{E}$

\section{INTRODUCTION}

Hidradenitis suppurativa (HS), also known as acne inversa, is a chronic, recurrent inflammatory skin disease. It usually manifests with painful, deep-seated, inflamed lesions in the axillary, inguinal, and anogenital regions. Depending on the stage of the disease, the nodules, abscesses, fistulas, sinus tracts, and scars are formed (1). The prevalence rates range between $1 \%$ to $4 \%$ in European countries and women are more frequently affected than men with a sex ratio of 3:1 $(2,3)$. However, new studies showed that men are suffering from severe HS more often than women (4). It occurs usually after puberty, mostly in the second decade of life (3). There are several phenotypes distinguished in HS, each of them has different severity and clinical manifestation (4). We know HS is associated with the disorders of follicular occlusion: acne conglobata, sinus pilonidalis, and dissecting cellulitis of the scalp, but connections with many other diseases are studied (5). The prognosis of HS depends on the intensity of the disease, but also on how early it is diagnosed and the therapy is set. To determine an adequate treatment, the pathogenesis of the disease needs to be elucidated.

Corresponding author: MUDr. Anna Ballová; e-mail: ballova26@uniba.sk

(c) 2021 Ballova A. et al.

This work is licensed under the Creative Commons Attribution-NonCommercial-NoDerivs 4.0 License (https://creativecommons.org/licenses/by-nc-nd/4.0/) 
In past, HS was thought to be an infectious disease of apocrine glands, but concepts on HS have changed over time. Nowadays, the follicular occlusion is considered the main pathogenetic mechanism followed by a secondary bacterial infection. It is assumed that the disease is triggered in a genetically predisposed individual by an environmental insults or internal factors, such as mechanical friction, cigarette smoking, obesity, and hormonal abnormalities $(6,7)$.

Recent findings suggest that HS should be viewed as a systemic inflammatory disease because of dysregulated immune response which leads to elevated levels of proinflammatory cytokines IL-1 $\beta$ (Interleukin), TNF- $\alpha$ (Tumour Necrosis Factor), and IL-10 in HS skin at even greater levels than in psoriatic skin and the elevation of cytokines was also find in the serum of the patients (8). We decided to investigate the possible association between elevated IgE and HS and to explore the patients' characteristics which can be related to high IgE levels.

\section{METHODS}

Patients with moderate to severe HS - PGA (Physician Global Assessment) stage from 3 to 5 followed up at our outpatient dermatology department from February 2015 to October 2020 were included in our study. Total IgE, IgA, IgG, and IgM serum levels as well as the inflammatory parameter CRP were measured in these. A personal and family history was taken. We searched whether these patients suffer from allergic diseases and smoke cigarettes. We also determined the basic parameters such as the weight and height of the patients. A single T-test was used for data analysis. A P-value $<0.05$ was considered as statistically significant. Total IgE was considered elevated if it was above the laboratory's upper normal level (>100 IU/ml). The control study group was not established because of a retrospective type of the study and it is currently not possible to set up a control group due to the epidemiological situation.

\section{RESULTS}

A total of 67 patients were included in the study. Out of the 67 patients $66 \%$ were male, which corresponds to a higher incidence of severe HS forms in men in new studies. The mean age (standard deviation) was $41.9( \pm 12.9)$ years and the mean duration of the disease was 15 years. The most commonly affected area was the axillary $(79.1 \%)$ and inguinal (64\%). In one patient, several areas were usually affected. The other affected sites included submammary, sacral, perineal, perianal, and scrotum. Forty-two $(62.7 \%)$ of the patients were smokers. Twenty patients $(29.8 \%)$ were overweight. Obesity was noticed in the same number of patients. Sinus pilonidalis was observed in eighteen (26.8\%) patients and acne conglobata in eleven (16.4\%) patients.

Elevated total IgE levels were noticed in 21 patients (31.3\%), of which 6 had a history of allergic disorder. Three of them had allergic rhinoconjunctivitis and the other three were suffering from atopic dermatitis. In our study the mean total IgE level was $203.0 \mathrm{IU} / \mathrm{ml}$ with a maximum value of $1,954 \mathrm{IU} / \mathrm{ml}$. Three patients had a concomitant elevation of IgE, IgA, and IgG levels. Total IgG level was elevated in 14 patients, 8 patients had total IgA elevation, and 1 patient had total IgM elevation. Mean total $\operatorname{IgE}$ was higher in smokers $(\mathrm{P}=0.81)$, in men $(\mathrm{P}=0.42)$, and in those with $\mathrm{CRP}$ higher than $10 \mathrm{mg} / \mathrm{l}(\mathrm{P}=0.50)$, but the $\mathrm{P}$-value was not significant for any of these hypotheses. The analysis of other factors (age, body mass index, and the number of affected areas, sinus pilonidalis and acne conglobata) did not show an association with increased IgE levels. We did not investigate the correlation of elevated IgE levels in the HS patients with the most severe PGA stage 5 as this group was very small. Investigated possible characteristics of HS patients associated with total IgE elevation are stated in the following table 1. 
Table 1 Possible characteristics of HS patients associated with total IgE elevation

\begin{tabular}{|l|c|c|c|}
\hline & $\begin{array}{c}\text { Total number of } \\
\text { patients }\end{array}$ & $\begin{array}{c}\text { Normal IgE } \\
\text { n46 (Mean \%) }\end{array}$ & $\begin{array}{c}\text { Elevation of IgE } \\
\text { n21 (Mean \%) }\end{array}$ \\
\hline Men & 44 & $27(58.7 \%)$ & $17(81.0 \%)$ \\
\hline Women & 23 & $19(41.3 \%)$ & $4(19.0 \%)$ \\
\hline Smokers & 44 & $30(65.2 \%)$ & $14(66.7 \%)$ \\
\hline Non-smokers & 23 & $17(37.0 \%)$ & $6(28.6 \%)$ \\
\hline CRP elevation & 21 & $14(30.4 \%)$ & $7(33.3 \%)$ \\
\hline Sinus pilonidalis & 18 & $11(23.9 \%)$ & $7(33.3 \%)$ \\
\hline Acne conglobata & 11 & $9(19.6 \%)$ & $2(9.5 \%)$ \\
\hline History of an allergic disorder & 17 & $11(23.9 \%)$ & $6(28.6 \%)$ \\
\hline
\end{tabular}

\section{DISCUSSION}

Elevated IgE levels are usually related to atopic diseases, but many other disorders such as helminth infections, immunodeficiency syndromes, and inflammatory diseases are also associated with higher IgE levels (9).

In 2015, a study describing an increase in serum levels of total IgE in about a third (37.4\%) of 99 patients with moderate to severe HS was published. Only one patient had a diagnosis of atopic dermatitis and one patient was suffering from asthma. The mean total $\mathrm{IgE}$ level was $186.4 \mathrm{IU} / \mathrm{ml}$. Previous studies show that the mean total IgE levels in the general population ranges from 32 to $41 \mathrm{IU} / \mathrm{ml}(10,11)$. Higher mean total IgE was in smokers (mean: $238.9 \mathrm{IU} / \mathrm{ml}$ vs. $59.4 \mathrm{IU} / \mathrm{ml}, \mathrm{P}=0.02)$, in men (267.2 IU/ml vs. $103.9 \mathrm{UI} / \mathrm{ml}, \mathrm{P}=0.04)$, and in those whose HS was not located on the groin (233.8 IU/ml vs. $146.8 \mathrm{UI} / \mathrm{ml}, \mathrm{P}=0.03$ ) (9). In our cohort we did not find a statistically significant association with any of these parameters. However, both studies included moderate-to-severe HS patients and it is a matter of further studies what results would be in cohort of mild-form HS.

To explain a possible association of total IgE elevation and HS, we studied available literature. In HS skin, we know there is an elevation of IL-1 $\beta$, TNF- $\alpha$, and IL-10. IL-10 is a major regulatory cytokine of inflammation which is elevated in HS lesions. We found out that IL10 enhances B-cell differentiation into plasma cells (12). Van der Zee et al, demonstrated a heavy inflammatory infiltrate in chronic HS skin lesions with a marked increase of CD20+ and CD79a+ B cells and CD138+ plasma cells. An increased number of tryptase-positive mast cells were also found in early and chronic lesions and in normal-appearing perilesional skin $(13,14)$. The plasma cells can produce the IgE detected in HS skin and can lead to an increase of $\operatorname{IgE}$ in serum. The enhancement of $\operatorname{IgE}$ production and infiltration of mast cells in HS skin could trigger a degranulation of these cells, releasing histamine and causing pruritus, a symptom which some HS patients experience (12).

\section{CONCLUSION}

Our study showed a higher mean value of total $\mathrm{IgE}$ in patients with moderate to severe HS than in the general population. However, we did not confirm an association with any 
characteristics of the patients. Limitations of this work include the small number of patients and lack of comparison with a control group, therefore further and more extensive studies are needed to support these results.

\section{REFERENCES}

1. Jemec GB. Clinical Practice. Hidradenitis Suppurativa. N Engl J Med 2012; 366 (2): 158-64.

2. Jemec GB, Heidenheim M, Nielsen NH. The prevalence of hidradenitis suppurativa and its potential precursor lesions. J Am Acad Dermatol 1996; 35 (2 pt 1): 191-4.

3. Canoui-Poitrine F, Revuz JE, Wolkenstein P et al. Clinical characteristics of a series of 302 French patiens with hidradenitis suppurativa, with an analysis of factors associated with disease severity. J Am Acad Dermatol 2009; 61 (1): 51-7.

4. Martorell A, Jfri A, Koster SBL et al. Defining hidradenitis suppurativa phenotypes based on the elementary lesion pattern: results of a prospective study. J Eur Acad Dermatol Venereol. 2020; 34(6): 1309-1318.

5. Pecova K. Acne Conglobata Associated with Hidradenitis Suppurativa, Disorders of Follicular Occlusion (Case Report). Acta Medica Martiniana. 2015; 15(2): 30-34.

6. Kurayev A, Ashkar H, Saraiya A, Gottlieb AB. Hidradenitis Suppurativa: Review of the Pathogenesis and Treatment. J Drugs Dermatol. 2016; 15(8): 1017-22.

7. Alikhan A, Lynch PJ, Eisen DB. Hidradenitis suppurativa: a comprehensive review. J Am Acad Dermatol. 2009; 60(4): 539-61.

8. Van der Zee HH, de Ruiter L, van den Broecke DG, et al. Elevated levels of tumour necrosis factor (TNF)- $\alpha$, interleukin (IL)-1 $\beta$ and IL-10 in hidradenitis suppurativa skin: a rationale for targeting TNF- $\alpha$ and IL-1 $\beta$. Br J Dermatol 2011;164:1292-8.

9. Pascual JC, García-Martínez FJ, Martorell A, et al. Increased total serum IgE levels in moderateto-severe hidradenitis suppurativa. Br J Dermatol. 2016; 175(5): 1101-1102.

10. Wittig HJ, Belloit J, De Fillippi I, Royal G. Age-related serum immunoglobulin E levels in healthy subjects and in patients with allergic disease. J Allergy Clin Immunol 1980; 66 (4): 305-13.

11. Hetman S, Kivity S, Greif J, et al. IgE values in the allergic and healthy Israeli population. Ann Allergy 1988; 61 (2): 123-8.

12. Kobayashi N, Nagumo H, Agematsu K. IL-10 enhances B-cell IgE synthesis by promoting differentiation into plasma cells, a process that is inhibited by CD27/CD70 interaction. Clin Exp Immunol 2002; 129 (3): 446-52.

13. Van der Zee HH, de Ruiter L, Boer J, et al. Alterations in leucocyte subsets and histomorphology in normal-appearing perilesional skin and early and chronic hidradenitis suppurativa lesions. $\mathrm{Br}$ J Dermatol 2012; 166 (1): 98-106.

14. Schlapbach C, Hänni T, Yawalkar N, Hunger RE. Expression of the IL-23/Th17 pathway in lesions of hidradenitis suppurativa. J Am Acad Dermatol 2011; 65 (4): 790-8.

Received: November, 10, 2020

Accepted: February, 2, 2021 